\title{
Os dilemas do ensino de Comunicação na Amazônia
}

\author{
The dilemmas of teaching Communication in the Amazon
}

Los dilemas de la enseñanza de la comunicación en la Amazonía

Gilson Vieira Monteiro ${ }^{1}$

\section{RESUMO}

Este artigo, quase um ensaio, contém algumas reflexões sobre os olhares e dilemas do ensino de Comunicação, registrando as idas e vindas, principalmente, do curso de Comunicação Social da Universidade Federal do Amazonas (UFAM), até se chegar à criação do Curso Bacharelado em de Mídias Digitais, da Universidade Federal do Sul da Bahia (UFSB), no Centro de Formação em Desenvolvimento Territorial (CFDT) do Campus Paulo Freire (CPF). É, mais que tudo, um conjunto de reflexões de quem tem 28 anos de experiência na docência superior em cursos de Graduação e Pósgraduação e se preocupa com os rumos do ensino de Comunicação, especificamente de Jornalismo, chegando, agora, a um novo olhar voltado para as Mídias Digitais.

PALAVRAS-CHAVE: ensino, educação superior, ecossistemas comunicacionais, mídias digitais.

\section{ABSTRACT}

This article, almost an essay, contains some reflections on the views and dilemmas of the teaching of Communication, recording the comings and goings, mainly, of the Social Communication course at the Federal University of Amazonas (UFAM), until the creation of the Bachelor Course in Digital Media, from the Federal University of the South of Bahia (UFSB), at the Training Center in Territorial

Submetido em: 17/10/2020 - Aceito em: 18/12/2020 - Publicado em: 25/01/2021

\footnotetext{
${ }^{1}$ Graduado em Comunicação Social pela Universidade Federal do Amazonas (1989), licenciado em Letras pela Universidade Federal do Amazonas (1992), mestre em Administração pela Universidade de São Paulo (1998) e doutor em Ciências da Comunicação pela Universidade de São Paulo (2003). Foi professor da Universidade Federal do Amazonas (Ufam) por quase 25 anos. Em 2017, foi redistribuído para a Universidade Federal do Sul da Bahia (UFSB), onde é professor Titular desde março de 2019. Atua no Campus Paulo Freire (CPF), na cidade de Teixeira de Freitas. Criou e lidera o Grupo de Estudos e Pesquisas em Ecossistemas Comunicacionais e as Tecnologias da Inteligência (ECOEM).
} 
Development (CFDT) of the Campus Paulo Freire (CPF). It is, above all, a set of reflections by those who have 28 years of experience in higher education in undergraduate and graduate courses and are concerned with the direction of the teaching of Communication, specifically in Journalism, now reaching a new looking towards Digital Media.

KEYWORDS: teaching, higher education, communication ecosystems, digital media.

\section{RESUMEN}

Este artículo, casi un ensayo, contiene algunas reflexiones sobre las visiones y dilemas de la enseñanza de la Comunicación, registrando los idas y venidas, principalmente, de la carrera de Comunicación Social de la Universidad Federal del Amazonas (UFAM), hasta la creación de la Licenciatura. en Medios Digitales, de la Universidad Federal del Sur de Bahía (UFSB), en el Centro de Capacitación en Desarrollo Territorial (CFDT) del Campus Paulo Freire (CPF). Se trata, sobre todo, de un conjunto de reflexiones de quienes cuentan con 28 años de experiencia en la educación superior en cursos de grado y posgrado y se preocupan por la dirección de la enseñanza de la Comunicación, específicamente en el Periodismo, alcanzando ahora una nueva dimensión. mirando hacia los medios digitales.

PALABRAS CLAVE: docencia, educación superior, ecosistemas comunicacionales, medios digitales.

\section{Introdução}

Sempre que se for discutir o ensino de Comunicação no Amazonas, não se pode deixar de registrar o pioneirismo da Universidade Federal do Amazonas (UFAM), especificamente, do Departamento de Comunicação Social (DECOM), hoje Faculdade de Informação e Comunicação (FIC) do antigo Instituto de Ciências Humanas e Letras (ICHL), hoje Instituto de Filosofia, Ciências Humanas e Sociais (IFCHS). Propor e aprovar o Programa de Pósgraduação em Ciências da Comunicação (PPG-CCOM) trouxe, pela primeira vez, a Pósgraduação em Comunicação na Região Norte. (ABUD, MONTEIRO e FEITOZA, 2012).

A área de concentração do Programa, Ecossistemas Comunicacionais, foi um sopro de inovação, no Brasil, na área de Comunicação, pouco compreendido, inclusive, internamente, o que levou o programa a fechar, dez anos depois. Deixou, porém, conceitos fundamentais como os de Ecossistemas Comunicacionais e Mídias Digitais, cunhados pelo professor Gilson Vieira Monteiro e que se tornaram fundamentais ao longo do tempo em publicações nacionais que atingiram revistas Qualis A2. Eis algumas das obras e artigos: Livro "Estudos e perspectivas 
dos ecossistemas na Comunicação"; livro "Comunicação Midiatizada na e da Amazônia"; artigo "Inquietações amazônidas: considerações para uma abordagem enativa da comunicação", em parceria com Sandro Colferai. Conferência "Ecossistemas comunicacionais: os dispositivos móveis como extensão do corpo humano", encerramento do Seminário Jornalismo para Dispositivos Móveis, na Universidade da Beira Interior, em Portugal, que se tornou capítulo do livro "Jornalismo para dispositivos móveis"; publicado na Revista da Fapcom/Paulus e Artigo "Epistemologia ecossistêmica e interdisciplinaridade: uma parceria necessária ao ensino escolar do século XXI, Publicado na revista Interdisciplinaridade, da PUC/SP. (Todos estes livros citados constam das "Referências" deste artigo).

Havia uma tentativa, digamos, de se arejar a área de Comunicação, para que os profissionais tradicionais, principalmente da área de jornalismo, entendessem que o mundo passava por mudanças e a área deveria ser revigorada. Em 2009, uma Comissão criada pelo Ministério da Educação, deu alguns passos para trás no ensino de Comunicação como uma área mais ampla e interdisciplinar, ao criar as Diretrizes Curriculares Nacionais (DCNs) para o curso de jornalismo que negam a Comunicação, as Mídias Digitais, o Cinema e o Marketing, por exemplo, como áreas de conhecimento. Particularmente, e não é de hoje, considero um retrocesso impensável para um mundo cada vez mais conectado e em redes. Ao invés de focar no processo de conhecimento, salutar para a área, a Comissão preferiu centrar os estudos da preservação da categoria profissional do jornalista. E ainda cometeu o pecado de trazer de volta o Estágio Supervisionado, antiga fonte de exploração de estudantes de Comunicação, especificamente de jornalismo, pelas empresas.

\section{A história do curso de jornalismo da UFAM}

É impossível falar em ensino de jornalismo, de modo genérico, sem estudar um pouco da história do Curso de Comunicação Social, hoje curso de Jornalismo, da antiga, Universidade do Amazonas (UA), hoje, Universidade Federal do Amazonas (UFAM). Criado em 1969, o curso foi implantado em 1970, ligado à extinta Faculdade de Filosofia, Ciências e Letras, que, ao longo do tempo, se transformou em Instituto de Ciências Humanas e Letras (ICHL), hoje Instituto de Filosofia, Ciências Humanas e Sociais (IFCHS). A primeira turma prestou Vestibular ainda em 1970. Foram ofertadas 30 vagas. 
A época da implantação foi marcada por convênios com a Escola de Comunicação e Artes (ECA) da Universidade de São Paulo (USP) e com a Universidade de Brasília (UnB), instituições que mandavam professores para ministrar disciplinas em Manaus. Da cidade, foram contratados como professores permanentes os jornalistas profissionais Raimundo Frânio Lima e Nélson Dimas Filho. Os primeiros ex-alunos do curso contratados pela universidade do Amazonas (UA) para ministrarem aulas foram, pela ordem, Walmir de Albuquerque Barbosa e Rui Souto Alencar.

Era denominado apenas Curso de Jornalismo. Em 1971 passou a se chamar Curso de Comunicação Social. Em 1972 foram definidas as habilitações de Jornalismo e Relações Públicas, que hoje são cursos da Faculdade de Informação e Comunicação (FIC). O curso enfrentou várias modificações no currículo, mas, só em 1995, duas mudanças radicais aconteceram: o aumento do número de vagas para 40 e a escolha da habilitação a partir do Vestibular. Atualmente, a seleção de ingressantes é feita por meio do Sistema de Seleção Unificada ( $\mathrm{SiSu})$.

\section{A realidade amazônica e o ensino}

Para se refletir sobre os problemas do ensino ao longo dos anos é preciso se associar aos problemas de uma realidade amazônica que é única. Em primeiro lugar, não se pode deixar de lado as condições histórico-sociais de um estado cuja dimensão é a de um País.

Os progressos da Zona Franca de Manaus (ZFM) hoje Pólo Industrial de Manaus (PIM), implantada em 1967, não dirimiram o problema da Comunicação do homem amazônico. Quando se fala em Comunicação, não se pode deixar de lado a Logística, afinal, é por meio de estradas, rios perfeitamente navegáveis e um sistema de comunicação eficaz que circulam as riquezas de uma Nação, Estado, País, Município, cidade ou até mesmo lugarejo. 
No Amazonas, e isso também se pode ampliar para a Amazônia, os problemas são triplicados. $\mathrm{O}$ acesso à maioria das cidades só pode ser feito por barco, as novidades demoram a chegar e, muitas vezes, nunca chegam. Enquanto isso, o caboclo da nascente de um rio possui antena parabólica, tem acesso a todos os programas de televisão mas não tem acesso aos produtos nela oferecidos. Há um paradoxo entre o motor de popa e o motor de luz que fica ligado, geralmente à noite, até que a emissora de TV saia do ar. Os sinais telefônicos já chegaram, assim como os smartphones. Porém, ainda é muito raro que um ser do beiradão tenha acesso à Internet.

Por mais que estejamos na era das Mídias Digitais, em geral, nas cidades do interior, as mensagens são passadas através de avisos de rádio, os barcos de recreio são especialistas em levar e trazer mensagens, e, além disso, a maioria das cidades é servida por um posto telefônico, que recebe e emite todas as ligações com o "mundo civilizado".

Esse quadro contrasta grandemente com Manaus, uma cidade de aproximadamente 3 milhões de habitantes, que abriga $97 \%$ da população economicamente ativa do Estado e centraliza praticamente todo o professor de produção de bens, serviços e consumo.

Foi a partir de 1969, dois anos após a implantação da Zona Franca de Manaus, no auge da euforia, que surgiu o Curso de Comunicação Social da Universidade do Amazonas, na verdade um curso de Jornalismo, solicitado pelo Sindicato dos Jornalistas, como se disse, que veio a receber sua primeira turma em 1970.

Como todos os cursos brasileiros de Comunicação Social, o da Universidade do Amazonas começa a repensar o seu papel, em 1972, a partir da inclusão da habilitação Relações Públicas: o curso não formaria apenas Jornalistas, formaria comunicadores. A partir daí, e com mais ênfase nos três últimos anos, o curso voltou os olhos para a iniciativa privada e começa a buscar parcerias para a execução de novos projetos e para aprender a conviver com a existência de outro curso de jornalismo na cidade, o da Faculdade Nilton Lins. Depois vieram os cursos da Faculdade Boas Novas, Faculdades Metropolitanas de Manaus (Fametro) e Uninorte.

Por ter, de início, se voltado apenas para a formação de jornalistas, o curso passou por um momento de discussão e busca renovar seus caminhos. Houve uma completa reformulação do currículo, que passa a dar mais ênfase à união entre a teoria e a prática. Um escritório-escola 
foi criado para prestar pequenos serviços de comunicação, ao mesmo tempo que permite aos acadêmicos e professores um contato maior com o mercado de trabalho.

Convênios e projetos de cooperação técnica foram firmados com o Instituto Euvaldo Lodi e com as empresas de comunicação para a maior interação entre o mercado de trabalho e a academia. Durante este período, o curso funcionou como uma pequena empresa: tinha Planejamento Estratégico, troca experiências com o outro curso de Comunicação Social da cidade e serviu de modelo de organização para a própria Universidade do Amazonas, mas, não atingiu o objetivo de eficácia e excelência na qualidade. Com as DCNs e a FIC, tenta se equilibrar em formar apenas jornalistas ou ampliar o olhar, de novo, para a Comunicação. Uma crise de identidade que atinge o ensino da área país afora.

\section{O abalo dos modos conflitantes de ver a profissão}

E esse não é um problema amazônico. Os cursos de Comunicação Social das universidades brasileiras parecem ter sofrido um abalo quando o diploma de Jornalismo começou a ser questionado. E esse abalo não se deveu apenas à questão do diploma. Ao que parece, os cursos ainda não abandonaram a velha filosofia da Escola de Frankfurt e o próprio conceito de Jornalismo não acompanha o avanço tecnológico e a nova visão de mundo, da empresa jornalística e do próprio conceito. Portanto, além dos problemas estruturais, a mim me parece que o maior problema do ensino de jornalismo venha a ser um conflito de filosofias, que ganharam força com as novas DCNs.

Debatendo-se para acompanhar os avanços teconológicos na área de Comunicação, os cursos de Comunicação Social, de uma maneira geral, estão perdendo o trem da história no que tange ao avanço dos conceitos. O professor Ciro Marcondes Filho, ao definir Jornalismo, é enfático: “...É uma maneira de se dar eco às posições pessoais, de classe ou de nações através de um complexo industrial-tecnológico, que além de preservar uma suposta impessoalidade, afirmase, pelo seu poder e soberania como a verdade" (MARCONDES FILHO, 1989, p. 11). 
E acrescenta: "O jornalismo, via de regra, atua junto com grandes forças econômicas e sociais: um conglomerado jornalístico raramente fala sozinho. Ele é ao mesmo tempo a voz de outros conglomerados econômicos ou grupos políticos que querem dar às suas opiniões subjetivas e particularistas o foro de objetividade" (IDEM, 1989, p. 11).

Enquanto isso, nas escolas, nós professores, preocupados com a "função social do jornalismo", fincamos o pé no mito da objetividade, da imparcialidade e da própria função social. Esquecemos que a notícia, na indústria do jornalismo moderno, é um mero produto, que passa por todas as fases de um produto empresarial moderno. Marcondes Filho, sobre o conceito de notícia, esclarece:

Notícia é a informação transformada em mercadoria com todos os seus apelos estéticos, emocionais e sensacionais; para isso a informação sofre um tratamento que a adapta às normas mercadológicas de generalização, padronização, simplificação e negação do subjetivismo. Além do mais, ela é um meio de manipulação ideológica de grupos de poder social e uma forma de poder político. Ela pertence, portanto, ao jogo de forças da sociedade e só é compreensível por meio de sua lógica. Essa lógica supõe três dimensões que abordarei neste trabalho: a) inserção da notícia como fator de sobrevivência econômica (infra-estrutura, portanto) do veículo (como mercadoria); b) como veículo ideológico; e c) como estabilizador político. (MARCONDES FILHO, 1989, p. 13).

Ao que parece, os cursos de Comunicação Social, alguns, agora, são só de jornalismo, das universidades brasileiras passaram a valorizar sobremaneira duas das três dimensões apontadas pelo professor Ciro Marcondes Filho: a notícia como veículo ideológico e a notícia como estabilizador político. A inserção da notícia como fator de sobrevivência econômica do veículo foi completamente deixada de lado ou pouco discutida. Entretanto, essa me parece ser a dimensão mais importante do jornalismo moderno e da Comunicação Social em si, nos dias atuais.

A empresa jornalística não é uma instituição de caridade. Tem por objetivo o lucro, como qualquer outra empresa. Logo, precisa ser vista e analisada como uma empresa. Neste caso, seu produto é a notícia, ou seja, "a informação transformada em notícia". E, embora essa afirmação possa provocar um certo desconforto em todos, no fundo, nós, professores de Jornalismo, estamos apenas repassando técnicas de como transformar uma informação em 
notícia, mais nada. Fazemos isso timidamente, mas procuramos centrar nossos discursos em sala-de-aula nas dimensões da notícia como veículo ideológico ou como veículo estabilizador político, ou não.

Esquecemos que a empresa jornalística faz parte do contexto de uma economia globalizada que, bem ou mal, é uma realidade irrefutável. Podemos até criticar o processo de globalização, mas não podemos ignorá-lo. E, em um mercado globalizado, é cada vez mais forte a necessidade de preocupação com a imagem sólida, bem cuidada, enfim, com uma imagem de seriedade junto aos consumidores. Mas, nos cursos de Comunicação Social, por muito tempo, ignorou-se essa dimensão empresarial do empreendimento jornalístico.

"A maioria das empresas ainda não atingiu plena maturidade em marketing. Essas empresas pensam que praticam marketing porque possuem um vice-presidente de marketing, gerentes de produtos, forças de vendas, orçamento de propaganda, e assim por diante. Mas um departamento de marketing não assegura que a empresa esteja orientada para o consumidor", nos diz Philip Kotler, ao analisar as empresas em geral.

E no caso da empresa jornalística, o que seria uma empresa voltada para o consumidor? É uma pergunta que ainda não tem resposta, certamente, porque, durante muito tempo, as empresas jornalísticas foram pouco estudadas como empresas.

Esse é um problema que precisa ser encarado de frente. Marshall McLuhan já alertava para o fato de que a informação não é mais um mero instrumento para a produção de bens econômicos, ao contrário, na sociedade moderna, é o principal dos bens econômicos. Umberto Eco vai além: "A Comunicação transformou-se em uma indústria pesada. Quando o poder econômico passa de quem tem em mãos os meios de produção para quem detém os meios de informação que podem determinar o controle dos meios de produção também o problema da alienação muda de significado. Diante da sombra de uma rede de comunicação que se estende para abraçar o universo, cada cidadão do mundo torna-se membro de um novo proletariado".

Não digo que os cursos de Comunicação Social tenham de perder o caráter contestador, que tenham de deixar de lado a questão da alienação. Mas, a mim me parece que todos os cursos estão sendo empurrados a se transformar em meras Escolas Técnicas de Jornalismo, das quais 
os alunos mal estão saindo com uma boa técnica de redação. Não digo também que os problemas de aparelhagem de laboratórios sejam menores. No entanto, o maior problema está no foco da formação dos profissionais.

Os cursos de Comunicação Social precisam deixar de formar apenas jornalistas. Precisam deixar de formar meros técnicos em Comunicação Social. É necessário que os próprios cursos passem a analisar o ambiente e vejam que o mundo moderno é o da telecomunicação e o da informática, numa junção pouco estudada, chamada de telemática.

É preciso, então, voltar os olhos para estudar essas transformações por que passam as empresas jornalísticas para poder garantir o mercado de trabalho aos profissionais que saem dos cursos e garantir a sobrevivência dos próprios cursos. É certo que as universidades públicas dificilmente conseguirão acompanhar a evolução tecnológica das empresas privadas. Mas, é hora de as parcerias começarem a ser buscadas.

As empresas jornalísticas não podem ser vistas como anjos. Mas também, não devem ser vistas como demônios. “...mesmo se os meios de comunicação, enquanto meios de produção, mudassem de dono. a situação de sujeição não mudaria. No máximo, é lícito suspeitar que os meios de comunicação seriam meios alienantes ainda que pertencessem à comunidade" (ECO, 1984).

Não me atrai o determinismo de Umberto Eco. No entanto, sou obrigado a concordar. não há muito o que fazer nessa sociedade da informação, diante do poder dos meios de comunicação de massa. Porém, não defendo a tese de que, por ser um meio intrinsecamente alienante, as escolas voltem os olhos apenas para as técnicas de "fazer jornal" ou para um teoricismo distante das técnicas, e esqueçam que o mundo gira e, o mundo da informação, numa velocidade alucinante, e, porque não dizer, alienante. E o mundo das Mídias Digitais é assim. E a Deep Web é o maior exemplo disso: espaço para a venda e consumo de todas as taras do ser humano.

Os problemas estruturas enfrentados talvez não tenham feito as escolas acordarem para o fato de que a previsão de Marshall McLuhan se transformou em fato: “...quando triunfam os meios de massa, morre o homem gutenberguiano e nasce um homem diferente, habituado a sentir o 
mundo de outro modo. Não sabemos se esse homem será melhor ou pior, mas sabemos que é um homem novo". (ECO, 1984).

É bom não esquecermos também que as escolas pouco têm de autonomia para modificar esse estado de coisas, determinado pelo Conselho Federal de Educação, hoje Conselho Nacional de Educação, que estabelece o currículo mínimo, todas as exigências para o funcionamento dos cursos mas não garante as verbas nem o aparelhamento dos laboratórios para que o cursos funcionem de acordo com suas próprias resoluções. Com isso, teoria e prática não se casam, com o agravante de que o professor é obrigado a ter dedicação exclusiva. Assim sendo, não se relaciona ativamente com o mercado de trabalho e os cursos de jornalismo passam a formar meros burocratas travestidos de pesquisadores.

"Em consequência desse teoricismo, os cursos darão ênfase mais à formação de técnicos administrativos do que de profissionais criativos em suas áreas de atuação. Com a oficialização da prática para efeito de, falando sobre ela e não mais dela, caracteriza-se o auge da burocratização que vem da origem dos cursos e da própria universidade brasileira, fundada com o diploma do rei Leopoldo" (MEDITISCH, 1992).

Talvez seja essa disfunção entre teoria e prática que tenha impedido os cursos de perceberem as modificações que estão ocorrendo no mundo, fora dos seus muros. Esse auge da burocratização, certamente impediu de as escolas perceberam que o mercado de trabalho para seus ex-alunos pode estar, por exemplo, nas empresas, não-apenas jornalismo, rádio, TV e Publicidade e Propaganda.

Essa não miopia não tem deixado enxergar que as empresas, em geral, sofrem de sérios problemas de comunicação que poderiam ser solucionados por profissionais de Comunicação. Pela falta de visão e de conhecimentos das técnicas de Comunicação, profissionais de Administração debatem-se com Endomarketing, Empowerment e outras modas do gênero e não conseguem resolver simples problemas de Comunicação, que afetam o desempenho interno e externo das organizações. 
Levados, certamente, pela lógica impositiva do sistema capitalista, a universidade em si, e nãoapenas os cursos de Comunicação, perderam a capacidade de ousar, de se aventurar, de buscar novos paradigmas de conhecimento, conforme Buarque (1994)

Acostumada a usar sua liberdade e a glorificar o conhecimento que produz, a universidade se mostra acuada: não avança na formulação de um novo papel, de uma nova estrutura. Não retoma o ponto interrompido há mil anos quando uma nova racionalidade foi produzida dentro das universidades medievais.

A universidade perde sua direção, fica perplexa e se diz em crise. os alunos perdem o interesse nos cursos, mudam de opções profissionais,c com o argumento de que o mercado já não apresenta a facilidade de emprego nem lhes oferece os salários anteriormente pagos. os professores perdem a motivação, dando como pretexto que os salários são insuficientes e as verbas para pesquisas limitadas.

O professor Cristovam Buarque diz que, em todos os cursos, os aspectos superficiais foram sendo ressaltado. O de Comunicação, por exemplo, teria se resumido a ser um curso de redação para divulgar informações oficiais. "Cada curso foi perdendo sua razão: razão epistemológica, em um mundo que avança aos novos campos onde o conhecimento não se submete às categorias tradicionais às quais a universidade está presa; e razão ética, porque não parecem ser instrumentos de um mundo melhor e mais belo - muitas vezes, ao contrário, são instrumentos de guerra, de opressão e desigualdade fabricada" (BUARQUE, 1994).

\section{Reflexões finais}

Certamente, todo esse sistema de dominação montando em torno da comunicação nos empurra a aceitarmos esse estado de coisas. A aceitarmos as limitações impostas pelo MEC, a nos escondermos por trás do escudo dos baixos salários. Porém, é preciso não esquecermos que o processo de comunicação é universal e que as mudanças do mundo moderno estão ocorrendo a uma velocidade inimaginável. Portanto, há lugar para um comunicador, nas empresas em geral e nas empresas de comunicação social. Buscar a ocupação desses mercados é o caminho. 
Não podemos ser ingênuos ao ponto de achar que uma mudança de foco, uma nova estratégia dos cursos de Comunicação Social irá diminuir os problemas. Ao contrário, é provável que eles até crescem. Mas é preciso ter consciência de que as mudanças de paradigma no mundo moderno empurram as escolas e as empresas para uma nova relação. Uma relação que, se não for de cooperação, tem que ser, pelo menos mais amistosa.

As soluções devem ser buscadas sem preconceitos. As universidades precisam se aventurar mais e mostrar que são importantes para as comunidades onde estão estabelecidas. A letargia tem que ser vencida e o gosto pela mudança recuperado. Buarque (1994) adverte:

De maneira geral, a comunidade universitária brasileira se divide entre conservadores-tradicionalistas e conservadores-revolucionários. Os primeiros acreditam que a universidade não necessita de mudanças, os outros consideram que essas mudanças já foram feitas. Os primeiros não vêem razão para buscar sintonizar a universidade com as necessidades e interesses da sociedade, os outros crêem que a universidade já está sintonizada, à medida que os reitores são eleitos diretamente.

O primeiro grupo se preocupa apenas com seu trabalho, como se os limites do mundo e do país não fossem além das fronteiras do campus universitário. O outro grupo se preocupa basicamente com o nível salarial e a falta de verbas, como se tudo o mais na universidade estivesse bem.

A hora é de os professores de comunicação social deixarem esses dois grupos de lado e criarem um terceiro. Não é necessária uma taxionomia para esse grupo, mas é preciso que seja comprometido com os avanços, com as novas tecnologias e com uma nova visão e mundo.

Uma nova visão dos processos de comunicação e, principalmente, uma visão mais avançada dos horizontes da comunicação. Ecossistemas comunicacionais e Mídias Digitais são conceitos que precisam ser estudados e incorporados à área. A mexida para trás dada como as DCNs de 2009 deve ser revista. Nem que seja da prática da docência.

Enquanto os cursos dormirem no berço esplêndido do letargismo e da formação de burocratas da comunicação, as empresas catarão, a dedo, profissionais de verdade para assumir seu 
departamento de marketing, seu sistema de informações. Enquanto isso, os alunos oriundos dos cursos de Comunicação Social mal sabem fazer um jornal de empresa, mas desconhecem o processo decisório de comunicação. Entendem muito bem um lide, respondem aos cinco Q mas não querem uma visão crítica dessa nova realidade mundial. Quando pouco, sabem lê-la.

É certo que, na área de jornalismo, avanços existiram. Mas, se examinarmos a história dos cursos de Comunicação Social no Brasil, esses avanços foram poucos e lentos. Tão lentos que o diploma de comunicador passou a ser questionado exatamente pela baixa qualidade dos profissionais. Também, é claro que não basta ter uma boa leitura do mundo, não basta ser um crítico de todo o processo dominante da comunicação, sem que a técnica tenha sido apreendida.

E este parece ser o dilema enfrentado pelas escolas e que nunca foi superado: unir teoria e técnica para a produção de notícias. $\mathrm{O}$ outro desafio e abrir caminhos para que o profissional saído das universidades não tenha que se submeter apenas às empresas jornalísticas. São três desafios que precisam ser vencidos com competência e criatividade.

Recentemente, no Centro de Formação em Desenvolvimento Territorial (CFDT), no Campus Paulo Freire (CPF), localizado na cidade de Teixeira de Freitas, no extremo Sul da Bahia, A Universidade Federal do Sul da Bahia (UFSB), criou o curso de Segundo Ciclo de Bacharelado em Mídias Digitais. Os avanços teóricos e de visão do mundo da Comunicação começam a surgir. É certo que professores e professoras deverão ser capacitados e preparados para enfrentar o próximo século e para enfrentar também as adversidades do processo de comunicação na Internet. E para enfrentar os desafios impostos pela nova era da telemática.

“...Algumas empresas jornalísticas estão percebendo que sabem muito pouco sobre por que as pessoas lêem jornais. Essas editoras estão fazendo pesquisas e tentando redesenhar o jornal para torná-lo contemporâneo, relevante e interessante para o leitor" (KOTLER, 1995). E nós, o que sabemos sobre o nosso público-alvo, os estudantes. Quantas pesquisa foram feitas para descobrir o que eles querem, se estão contentes com os cursos, o que precisa mudar, que direção deve ser tomada. Certamente, não conhecemos. Provavelmente, não temos metas a serem atingidas, não temos um planejamento formal e o compromisso de atingi-los. 
O curso de curso de Bacharelado em Mídias Digitais da UFSB já nasce a partir de um planejamento sério e de um compromisso com as metas a serem a tingidas. Ainda que de forma não muito clara, talvez por intuição dos professores e professoras que participaram do Grupo de Trabalho (GT) de criação do Curso, começou a adotar uma visão, um conceito de marketing.

“O propósito do conceito de marketing é ajudar as organizações a atingir suas metas.

No caso de empresas particulares, a meta principal é o lucro; no caso das organizações que não visam o lucro e públicas, é a sobrevivência e a atração de fundos suficientes para desempenhar seu trabalho". (KOTLER, 1995).

Não digo que a filosofia do marketing, que já começa a ser implantada no curso de Mídias Digitais da UFSB e, certamente, é praticada em outros cursos das universidades brasileiras seja a panacéia para os problemas. Porém, é um caminho. E que passa ao largo desse discurso paranóico da privatização. Buscar parceirias, buscar recursos externos que garantam a sobrevivência e o funcionamento dos cursos nada tem que ver com privatização.

A mudança de filosofia, de visão, de cultura, é lenta, gradual, mas, parece ser a saída, ou melhor, a entrada. Para se explorar o mundo dos ecossistemas comunicacionais. A adaptação à nova realidade é o primeiro passo para vencermos o isolamento e a letargia. As dificuldades são muitas e reconhecidas por todos. Superá-las é o desafio. Vencer a falta de equipamentos com criatividade e competência não é difícil. Quase impossível é vencer os "conservadorestradicionalistas e os conservadores-revolucionários".

\section{REFERÊNCIAS}

ABUDD, Maria Emília de O. MONTEIRO, Gilson. Pereira, FEITOZA, Mirna (Orgs). Estudos e perspectivas dos ecossistemas na comunicação. Manaus: Ufam, 2012.

BUARQUE, Cristovam. A Aventura da Universidade. Paz e Terra Unesp, São Paulo, 1994. 
COLFERAI, Sandro Adalberto. "Isolamento revisitado: as disparidades no acesso às tecnologias da Comunicação na Amazônia Brasileira", apresentado no GT 10 "Comunicación, Tecnologia y Desarrollo" do "XI Congreso Latinoamericano de Investigadores de La Comunicación" que aconteceu entre os dias 09 e 11 de maio, na cidade de Montevidéu, Uruguai.

COLFERAI, Sandro Alberto e MONTEIRO, Gilson Vieira. A crise da invenção e a invenção na crise: inferências para uma pesquisa amazônida. Aceito para o simpósio Comunicação e Cultura, durante o $4^{\circ}$ SILIC - Simpósio de Literatura Brasileira Contemporânea, a ser realizado no período de 21 a 24 de agosto de 2013, na Universidade Federal de Rondônia, no campus de Vilhena.

COLFERAI, Sandro Adalberto. MONTEIRO, Gilson Vieira. "Por uma pesquisa amazônica em Comunicação: provocações para novos olhares", de Gilson Vieira Monteiro e Sandro Alberto Colferai. Capítulo do livro "Comunicação Midiatizada na e da Amazônia", organizado por Maria Ataíde Malcher, Netília dos Anjos Seixas, Regina Lúcia Ales de Lima e Otacílio Amaral Filho. Belém: Scriba/Fadesp, 2011.

COLFERAI, Sandro Adalberto. Um jeito amazônida de ser mundo - a Amazônia como metáfo- ra do ecossistema comunicacional: uma leitura do conceito a partir da região. Tese (doutorado) - Universidade Federal do Amazonas, Instituto de Ciências Humanas e Socias, Pós-Graduação em Sociedade e Cultura na Amazônia, 2014.

COLFERAI, S. MONTEIRO, G. Inquietações amazônidas: considerações para uma abordagem enativa da comunicação. Rev Famecos (Online). Porto Alegre, v. 23, n. 1, janeiro, fevereiro, março e abril de 2016.

DANTAS, J. ; MONTEIRO, Gilson . Ecossistemas comunicacionais: uma visão prática . In: Gilson Vieira Monteiro; Maria Emília de Oliveira Pereira Abbud; Mirna Feitoza Pereira. (Org.). Estudos e perspectivas dos ecossistemas na comunicação. 1ed.Manaus: Editora da Universidade Federal do Amazonas, 2011, v. 1, p. 123-137.

DANTAS, Jane Santos; MONTEIRO, Gilson. Ecossistemas comunicacionais: uma visão prática. In: MONTEIRO, Gilson; ABUDD, Maria Emília de O. Pereira; FEITOZA, Mirna (Orgs). Estudos e Perspectivas dos Ecossistemas na Comunicação. Manaus: Ufam, 2012.

KOTLER, Philip. Administração de Marketing - análise, planejamento e controle. São Paulo, Atlas, 1995.

LIMA, Kátia de; MONTEIRO, Gilson. Epistemologia ecossistêmica e interdisciplinaridade: uma parceria necessária ao ensino escolar no século XXI. In: 
Interdisciplinaridade - São Paulo, no. 12, pp. 01-129, abr. 2018.

http://revistas.pucsp.br/index.php/interdisciplinaridade

MARCONDES FILHO, Ciro. O Capital da Notícia - Jornalismo como produção social da segunda natureza. 2 ed. Ática, São Paulo, 1989.

MEDITSCH, Eduardo. O conhecimento do Jornalismo. Editora da UFSC, Santa Catarina, 1992.

MONTEIRO, Gilson (Org.); ABBUD, M. E. O. P. (Org.) ; PEREIRA, M. F. (Org.) . Estudos e perspectivas dos Ecossistemas na Comunicação. 1. ed. Manaus: Editora da Universidade Federal do Amazonas, 2011. v. 1. 281p .

MONTEIRO, Gilson Vieira. "Midias digitais, ecossitemas comunicacionais vivos e o consumo de informações", apresentado no GT Economía Política de las Comunicaciones do "XI Congreso Latinoamericano de Investigadores de La Comunicación" que aconteceu entre os dias 09 e 11 de maio, na cidade de Montevidéu, Uruguai.

MONTEIRO, Gilson Vieira. "Ecossistemas, mídias digitais e o Ecoem da Ufam", de Gilson Vieira Monteiro, apresentado no $11^{\circ}$ Encontro Internacional de Arte e Tecnologia (\#11.ART): homo aestheticus na era digital, realizado no Auditório 2 do Museu Nacional da República, de 2 a 7 de outubro de 2012, em Brasília.

MONTEIRO, Gilson Vieira. "A cultura hacker e as possibilidades da Extensão nas Mídias Digitais", trabalho apresentado no 5 CBEU - UFRGS - Porto Alegre - 9/11/2011 na Mesa "" Fronteiras da cultura".

MONTEIRO, Gilson Vieira. "Panorama do Rádio em Manaus". Capítulo do livro "Panorama do Rádio no Brasil, organizado por Nair Prata, Volume 1, Florianópolis: Editora Isular, 2011.

MONTEIRO, Gilson. Ecossistemas comunicacionais: os dispositivos móveis como extensão da mente humana. Conferência de encerramento do "CONGRESSO INTERNACIONAL SMARTPHONES/TABLETS/WEB 2.0/CONVERGÊNCIA UNIVERSIDADE DA BEIRA INTERIOR 2 E 3 DE DEZEMBRO DE 2014.

MONTEIRO, Gilson. Ecossistemas comunicacionais: os dispositivos móveis como extensão do corpo humano. In: CANAVILHAS, J. SATUF, I (ORGs). Jornalismo para Dispositivos Móveis: produção, distribuição e consumo. Covilhã, ubi, labcom, livros labcom- Portugal 2015. pp. $43-60$. 
MONTEIRO, Gilson. Mídias Digitais e as tecnologias da sobrevivência. In: Paulus Revista de Comunicação da FAPCOM. Volume 1 - No 1 - $1^{\circ}$ semestre 2017. Páginas 109 a 120.

NASCIMENTO, CMB; MONTEIRO, G. Thiago de Mello na Mídia: poesia viva e insubmissa. II Conferência Sul-Americana - VII Conferência Brasileira. "Amazônia e o direito de comunicar" 17 a 22 de outubro de 2011 - Belém/PA.

Este é um artigo de acesso aberto distribuído sob os termos da Licença Creative Commons Atribuição Não Comercial-Compartilha Igual (CC BY-NC- 4.0), que permite uso, distribuição e reprodução para fins não comerciais, com a citação dos autores e da fonte original e sob a mesma licença. 